\title{
Experimental ground source heat pump system to investigate heat transfer in soil
}

\author{
Hakan Demir ${ }^{*}$, Ş. Özgür Atayılmaz, Özden Ağra \\ Ylldız Technical University, Istanbul, Turkey \\ * Corresponding author. Tel: +90 21238328 20,Fax: +90 21226166 59,E-mail: hdemir@yildiz.edu.tr
}

\begin{abstract}
The earth is an energy resource which has more suitable and stable temperatures than air. Typical values for Coefficient of Performance (COP) of Ground Source Heat Pumps (GSHPs) are up to 8 while it is 4 of air source heat pumps. GSHPs were developed to use ground energy for residential heating. The most important part of a GSHP is the Ground Heat Exchanger (GHE) that consists of pipes buried in the soil and is used for transferring heat between the soil and the heat exchanger of the GSHP. Soil composition, density, moisture and burial depth of pipes affect the size of a GHE. Design of GSHP systems in different regions of US and Europe is performed using data from an experimental model. However, there are many more techniques including some complex calculations for sizing GHEs. An experimental study was carried out to investigate heat transfer in soil. Measured fluid inlet temperatures were used in the numerical simulation and the fluid outlet temperatures were calculated. A parametrical study was conducted to investigate effects of soil thermal properties and geometrical parameters on heat transfer from ground heat exchanger. It is seen that the soil thermal conductivity has great importance on heat transfer. Also, burial depth and distance between pipes are other parameters to be considered for sizing GHEs.
\end{abstract}

Keywords: Ground source heat pump, Parallel pipe horizontal ground heat exchanger, Numerical solution

\section{Introduction}

The GHE is an important part of GSHP systems and its dimensions and burial depth should be calculated with an effective method. Particularly, the cost of assembly of GHE affects the choice of these systems. In the literature, there are two kinds of analytical approaches: Kelvin Line Source Theory and Cylindrical Source Theory. In addition, there are many studies using two or three dimensional steady state and time dependent numerical techniques [1-7], [8-11, 12]. Kelvin Line Source and Cylindrical Source theories find only symmetrical soil temperature distributions around the pipe. Metz [7] has been suggested an analytical model to find temperature distribution in the soil by dividing ground into blocks around the coil and done some modifications to Line Source theory. Mei [6] has been included the effects of seasonal ground temperature variation, pipe material, circulating liquid properties and compared his work with modified line source and simple line source models. A simplification of boundary conditions to solve equations analytically causes some error on results especially shorter simulation times. Analytical models do not consider the temperature change of soil by depth and the surface effects such as radiation, convection and surface cover. The effects of the convection on the ground surface were included in some of the models $[1,2]$. A more complicated model for heat transfer of buried pipes was performed by Negiz, Hastaoglu and Heidemann for petrol transferring pipes $[4,9,10]$. Piechowsky was included mass transfer in his model to take into account the effects of the soil moisture $[11,13]$. In this study, a numerical model was suggested with realistic boundary conditions. In order to validate the new model a big scale experimental set area was built.

\section{Experimental study}

A GSHP having $4 \mathrm{~kW}$ heating and $2.7 \mathrm{~kW}$ cooling capacity is used for experimental study. The ground heat exchanger consists of three parallel pipes which have $40 \mathrm{~m}$ length and $1 / 2$ " diameter buried in soil at $1.8 \mathrm{~m}$ depth. The distance between the parallel pipes is $3 \mathrm{~m}$. Experimental GSHP system is installed at Yıldız Technical University Davupaşa Campus on 
$800 \mathrm{~m}^{2}$ surface area with no special surface cover. Temperature data were collected using Ttype thermocouples buried in soil horizontally and vertically at various distances from the pipe center and at the inlet and outlet of the ground heat exchanger. All the thermocouples are connected to a $64 \mathrm{c}$ hannel PLC system capable of saving data of hourly temperature measurements for 8 days. Figure 1 and 2 represents the experimental setup.

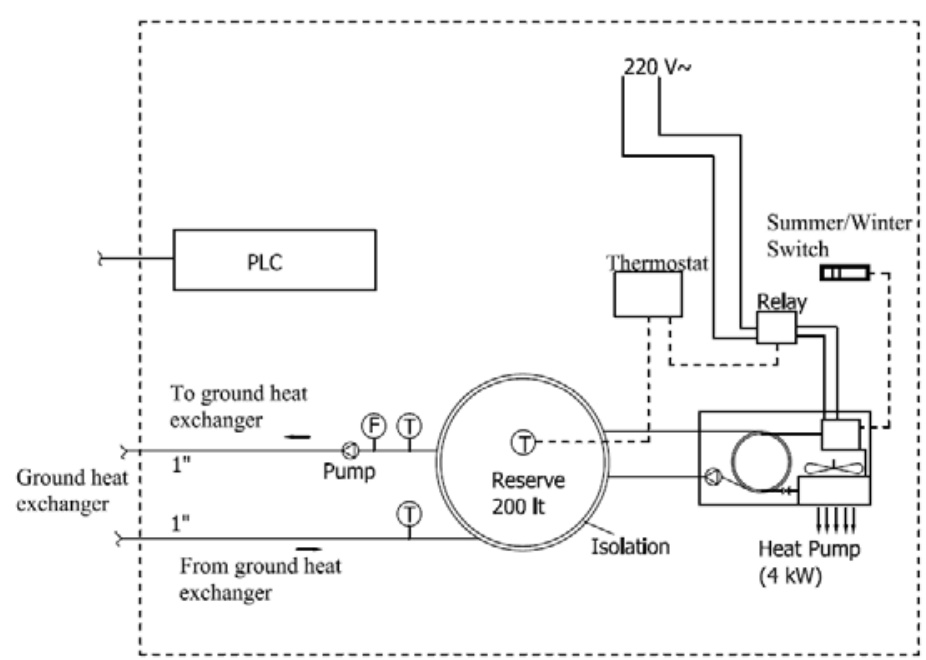

Figure 1 Experimental setup (heat pump and measuring system) [14]

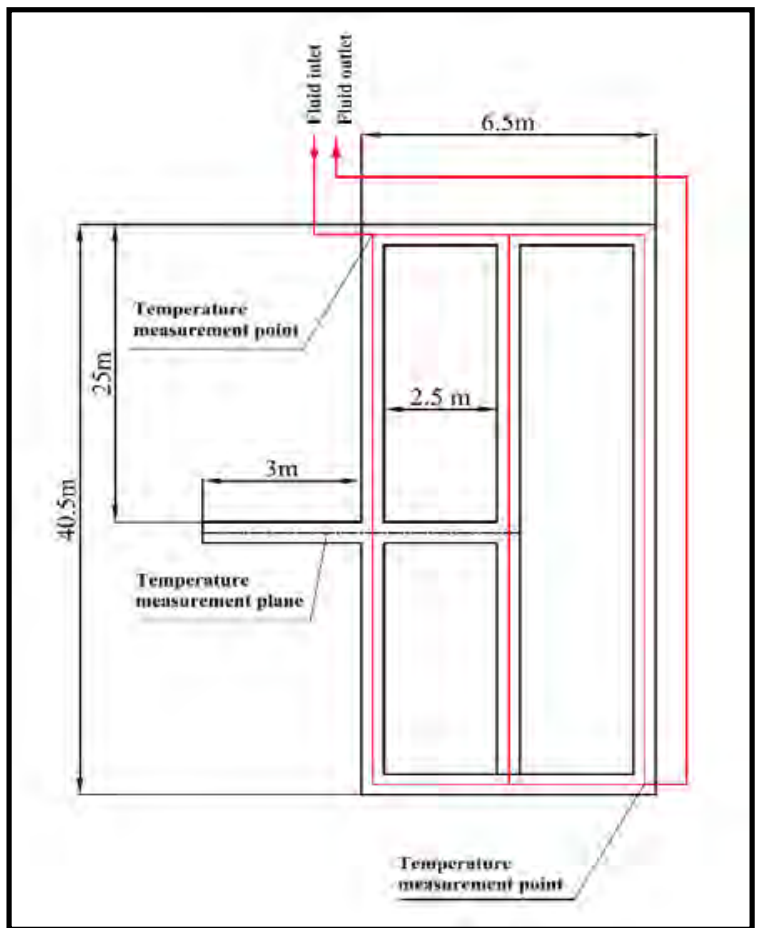

Figure 2 Experimental setup (ground heat exchanger and thermocouple locations) [14]

\section{Numerical study}

Aiming to find three dimensional temperature distributions in the soil, a new model with realistic boundary conditions was suggested. Heat transfer in the soil is time dependent three dimensional heat conduction. Temperature gradient along the pipe axis is so small that it can be neglected and the heat conduction equation can be solved using dynamical boundary conditions in two-dimensional geometry. The solution domain and boundary conditions was prepared as in Figure 3. 


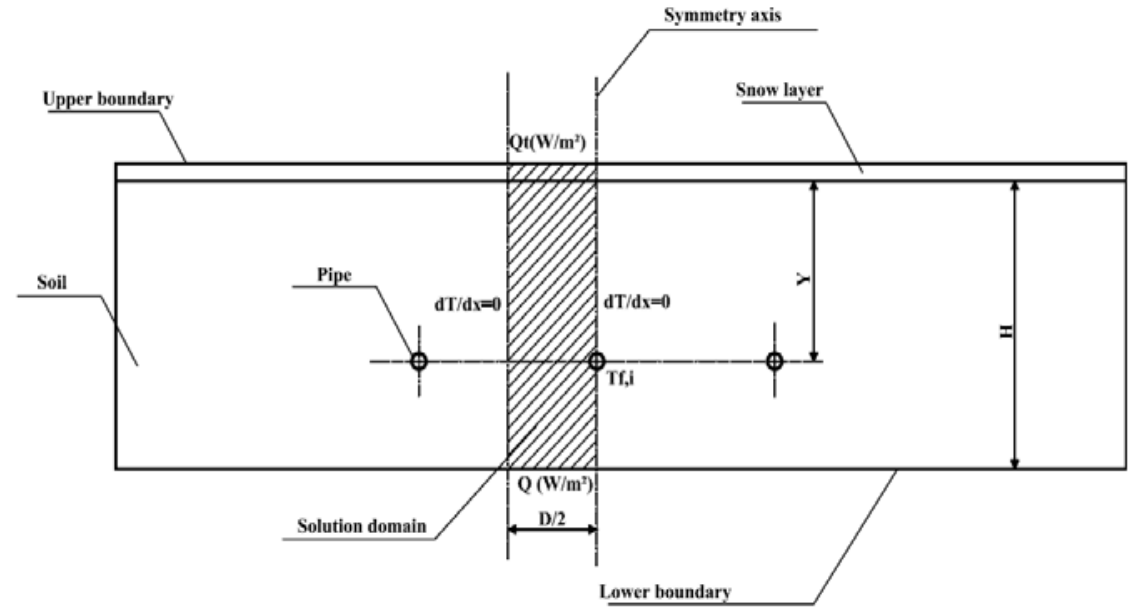

Figure 3 Parallel pipe horizontal GHE and solution area in the soil [14]

The model consists of parallel pipes buried at the depth of Y. Distance between pipes is D. Region shown in Figure 4 is taken as solution domain. This is two dimensional and presented in Cartesian coordinate system.

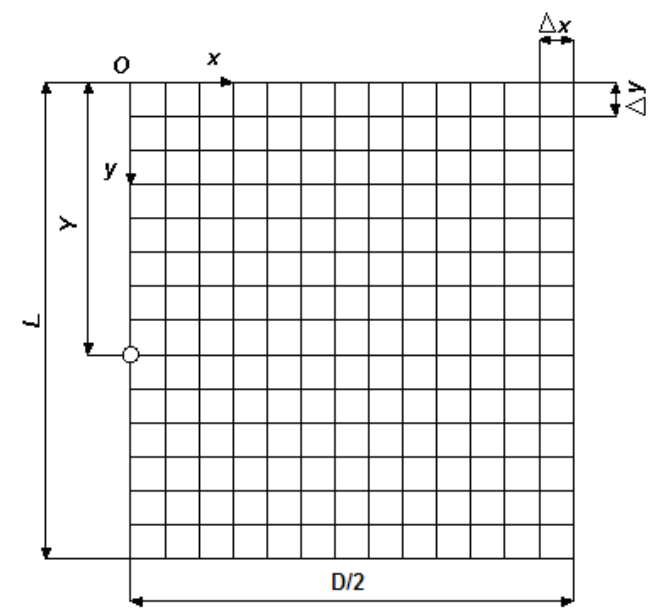

Figure 4 Computational solution domain [14]

Two-dimensional time dependent heat conduction and boundary conditions of problem are of the form;

$\frac{\partial^{2} T}{\partial x^{2}}+\frac{\partial^{2} T}{\partial y^{2}}=\frac{1}{\alpha} \frac{\partial T}{\partial t}$

$T_{i}=T(x, t) @ t=0$

$\left.\frac{\partial T}{\partial x}\right|_{x=D / 2}=0$

$\left.\frac{\partial T}{\partial x}\right|_{x=0}=0$

$Q\left(W / m^{2}\right) @ y=L$

$Q_{t}\left(W / m^{2}\right) @ y=0$ 
$T_{f, i}=C$

Where $\mathrm{Q}_{\mathrm{t}}$ is total heat transfer rate at the surface and $\mathrm{T}_{\mathrm{f}, \mathrm{i}}$ is the fluid inlet temperature. Because of the complexity of the boundary conditions, the heat conduction equation has been solved numerically using Alternating Direction Implicit (ADI) Finite Difference formulation. ADI method is stable for every time step and grid size and the resulting matrix system is tridiagonal. Tri-diagonal matrix systems can be solved easily using the Thomas algorithm. For this purpose, software was developed in MATLAB environment and the effects of solution parameters on the results were investigated. Details of the numerical model and solution procedure can be found in Demir et.al. [14]. The simulation results were acceptable when a mesh size of $0.1 \mathrm{~m}$ in $\mathrm{x}$ and $\mathrm{y}$ directions, $1 \mathrm{~m}$ in $\mathrm{z}$ direction and $1800 \mathrm{~s}$ as time step were used. Parameters from experimental study used in numerical simulation as below:

- Start date 13th December - Length of parallel pipes, $\mathrm{L}=40 \mathrm{~m}$

- Volumetric flow rate, $\mathrm{V}_{\mathrm{f}}=0.42768 \mathrm{~m}^{3} / \mathrm{h} \quad$ - Distance between pipes, $\mathrm{D}=3 \mathrm{~m}$

- Soil thermal conductivity, $\mathrm{k}_{\mathrm{s}}=2.18 \mathrm{~W} / \mathrm{m} \mathrm{K} \quad$ - Burial depth, $\mathrm{Y}=1.8 \mathrm{~m}$

- Soil thermal diffusivity, $\alpha_{\mathrm{s}}=0.00000068 \mathrm{~m}^{2} / \mathrm{s}$ - Working fluid is water

- Pipe outer/inner diameter, $\mathrm{d}_{\mathrm{o}} / \mathrm{d}_{\mathrm{i}}=20 / 14.6 \mathrm{~mm} \quad$ - Pipe material $=$ PPRC

- Pipe thermal conductivity, $\mathrm{k}_{\mathrm{p}}=0.8999 \mathrm{~W} / \mathrm{m} \mathrm{K}$ - Number of parallel pipes, $\mathrm{n}=3$

\section{Results}

The experimental fluid inlet/outlet and theoretical fluid outlet temperatures are shown in Figure 5. It is seen that the experimental and numerical results are in good agreement.

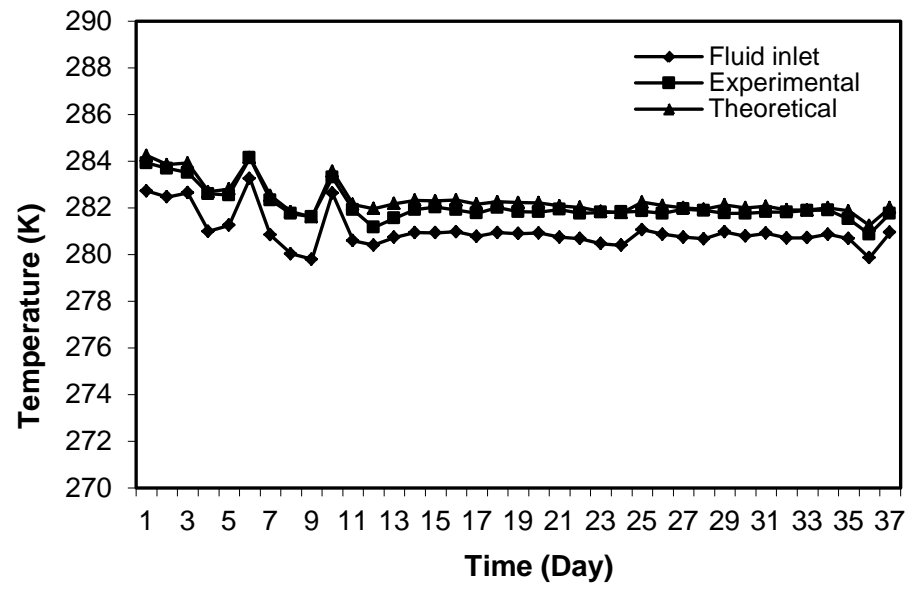

Figure 5 Experimental fluid inlet and experimental/theoretical fluid outlet temperatures [14]

The effects of the parameters, soil thermal conductivity, burial depth and distance between pipes were investigated numerically. Figure 6 and $7 \mathrm{~s}$ how the effects of soil thermal conductivity on fluid outlet temperature and horizontal temperature distribution in soil. Fluid outlet temperature increases with increasing thermal conductivity while has no e ffect on horizontal temperature distribution after $250 \mathrm{~h}$ of simulation time. 


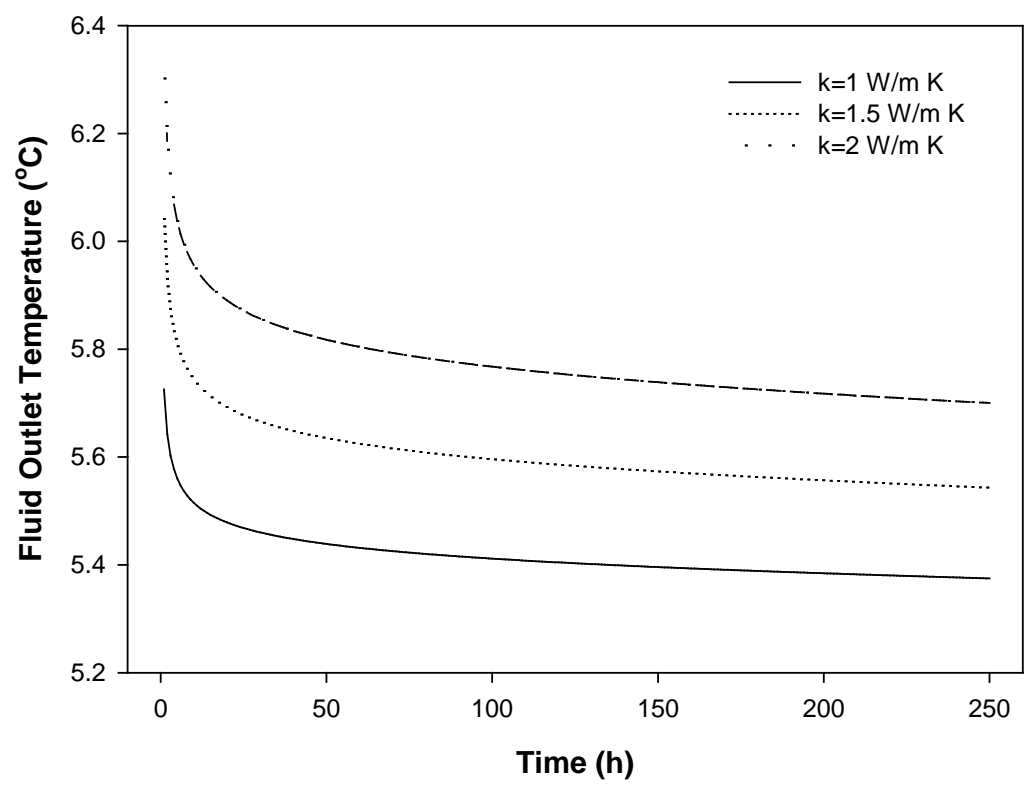

Figure 6 Effects of the soil thermal conductivity on fluid outlet temperature

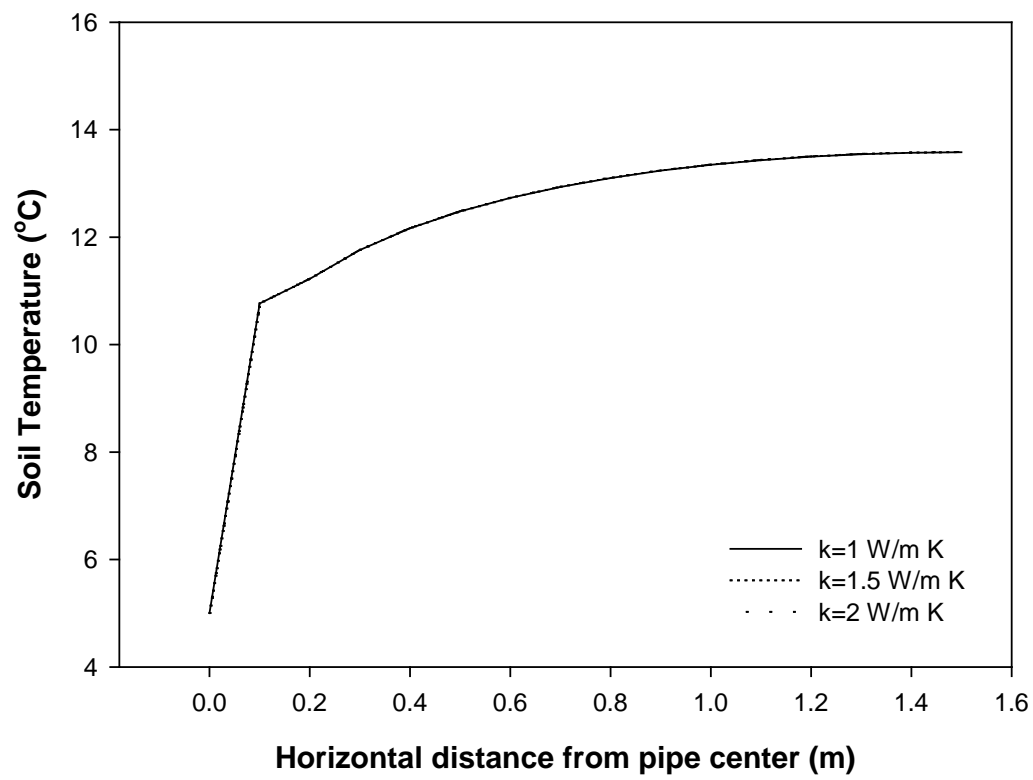

Figure 7 Effects of the soil thermal conductivity on horizontal temperature distribution in soil

In Figure 8 and 9, the effects of the distance between pipes on fluid outlet temperature and horizontal temperature distribution in soil are presented. Fluid outlet temperature increases with increasing distance. Also, it is seen from Figure 9 that increasing the distance between pipes affects the unaffected soil region and heat transfer characteristics. Smaller distances cause decrease of the temperature of the soil in the vicinity of the pipes and reduces heat transfer rate. 


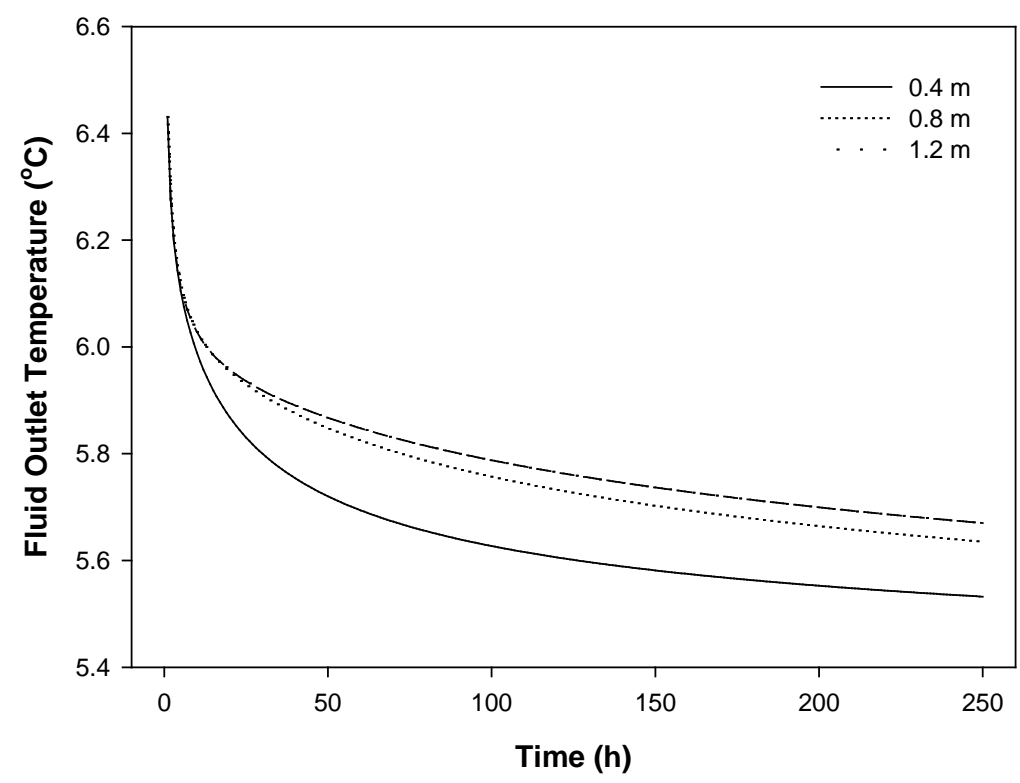

Figure 8 Effects of the distance between pipes on fluid outlet temperature

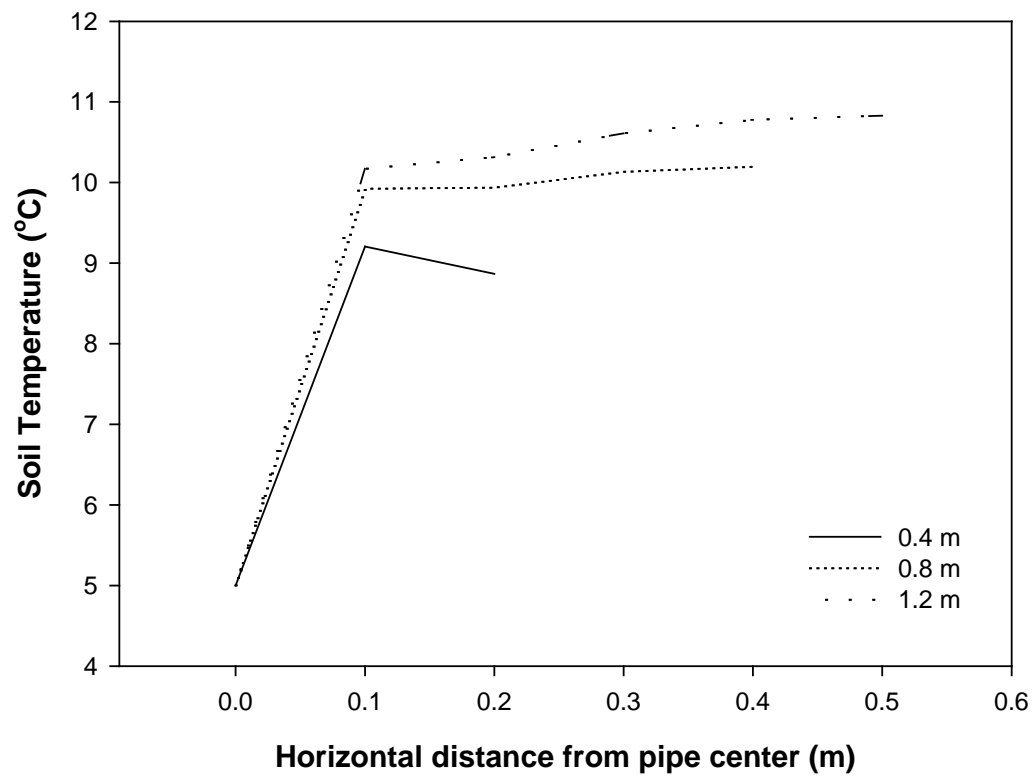

Figure 9 Effects of the distance between pipes on horizontal temperature distribution in soil

In Figure 10 and 11, the effects of the burial depth on fluid outlet temperature and horizontal temperature distribution in soil are shown. Fluid outlet temperature increases with increasing burial depth. It is easily seen the effects of surface temperature variations on the fluid outlet temperature for the burial depth of $0.5 \mathrm{~m}$. Therefore, it is recommended that the minimum burial depth must be $1 \mathrm{~m}$ for horizontal ground heat exchangers. Also, increasing the burial depth increases the fluid outlet temperature as the temperature of the soil increase with depth.

\section{Conclusions}

In this study, the numerical model including all weather conditions was suggested and verified with the experimental study. The most important advantage of the model is implementation of meteorological data to numerical model. It is seen that the maximum deviation between calculated and experimental fluid outlet temperatures is $10.5 \%$. It is 
possible to simulate whole year operation of ground heat exchanger providing the meteorological data.

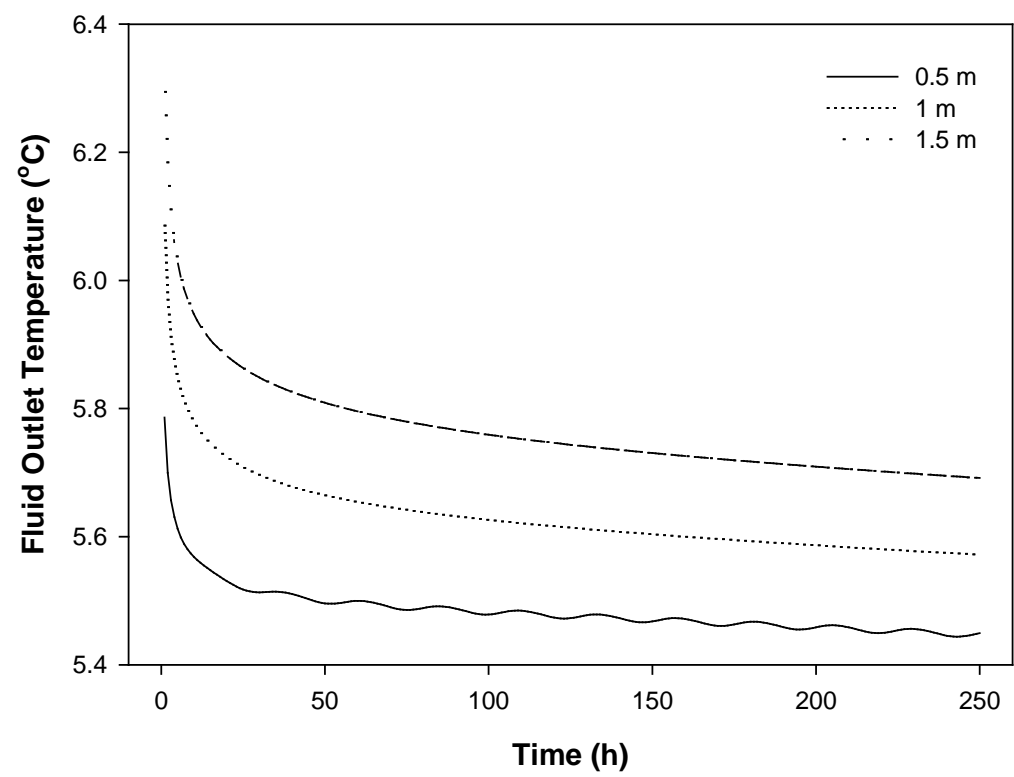

Figure 10 Effects of the burial depth pipes on fluid outlet temperature

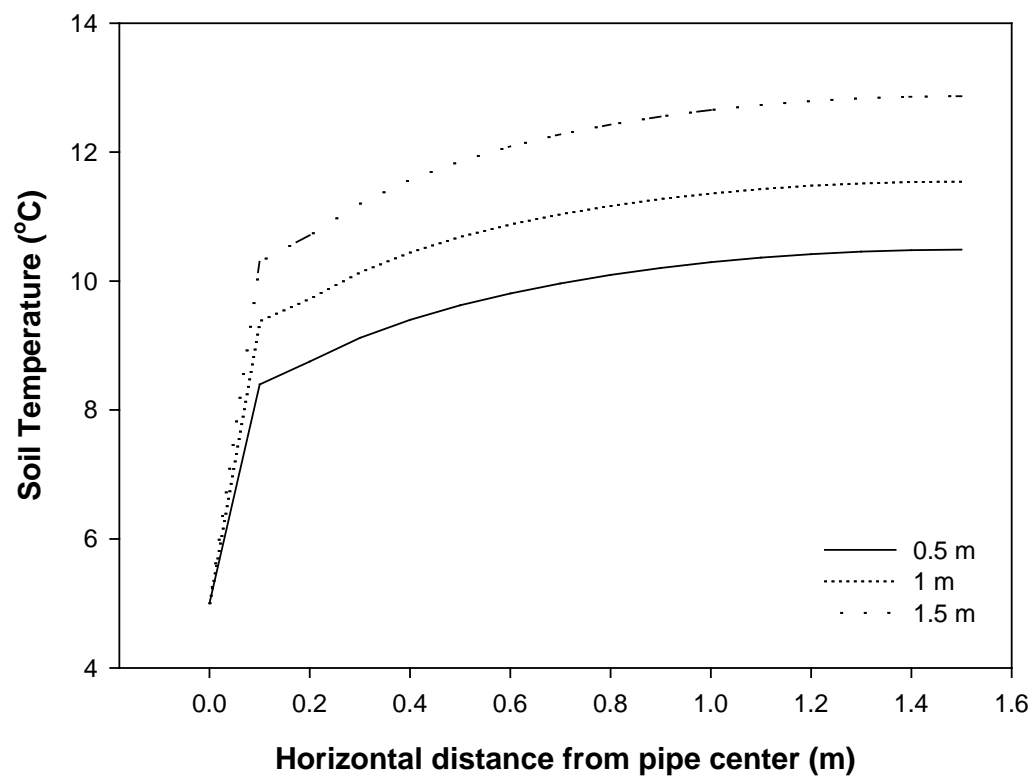

Figure 11 Effects of the burial depth pipes on horizontal temperature distribution in soil

After validating the numerical model, a parametrical study was conducted to investigate effects of the geometrical parameters and soil properties. It is determined that the fluid outlet temperature is strongly depends on soil thermal conductivity. The heat transfer characteristics of the soil in the vicinity of the pipes can be improved by using backfill material. Other important parameters are burial depth and distance between the pipes. Pipes should be buried in the soil below $1 \mathrm{~m}$ from the free surface in order to eliminate surface effects such as temperature variation, radiation, snow and rainfall. Also, the distance between pipes should not less than $0.8 \mathrm{~m}$ considering the required surface area. 
To improve the accuracy of the model neural network approach may be used for modeling soil, air temperature and solar radiation. Also, moisture transfer and variation of soil thermal conductivity with soil moisture content and temperature can be modeled for further studies.

\section{References}

[1] B. Bohm, On transient heat losses from buried district heating pipes, Int. Journal of Energy Research 24 (2000), pp. 1311-1334

[2] M. Chung, P.S. Jung, R.H. Rangel, Semi-analytical solution for heat transfer from a buried pipe with convection on the exposed surface, Int. Journal of Heat and Mass Transfer 42 (1999), pp. 3771-3786

[3] Y. Gu, D.L. O'Neal, An analytical solution to transient heat conduction in a composite region with a cylindrical heat source, Transactions of the ASME 117 (1995), pp. 242-248

[4] M.A. Hastaoglu, A. Negiz, R.A. Heidemann, Three-dimensional transient heat transfer from a buried pipe - part III comprehensive model, Chemical Engineering Science 50 (1995), pp. 2545-2555

[5] T.K. Lei, Development of a computational model for a ground-coupled heat exchanger, ASHRAE Transactions: Research 99 (1993), pp. 149-159

[6] V.C. Mei, Heat transfer of buried pipe for heat pump application, Journal of Solar Energy Engineering 113 (1991), pp. 51-55

[7] P.D. Metz, A Simple computer program to model three-dimensional underground heat flow with realistic boundary conditions, Transactions of the ASME 105 (1983) ), pp. 4249

[8] S. Mukerji, K.A. Tagavi, W.E. Murphy, Steady-state heat transfer analysis of arbitrary coiled buried pipes, Journal of Thermophysics and Heat Transfer 11 (1997), pp. 182-188

[9] A. Negiz, M.A. Hastaoglu, R.A. Heidemann, Three-dimensional heat transfer from a buried pipe - I. laminar flow, Chemical Eng. Science 48 (1993), pp. 3507-3517

[10]A. Negiz, M.A. Hastaoglu, R.A. Heidemann, Three-dimensional transient heat transfer from a buried pipe: solidification of a stationary fluid, Numerical Heat Transfer 28 (1995), pp. 175-193

[11]M. Piechowsky, Heat and mass transfer of a ground heat exchanger: theoretical development, Int. Journal of Energy Research 23 (1999), pp. 571-588

[12]A.D. Chiasson, Advances in Modeling of ground source heat pump systems, MSc Thesis, Oklahoma State University, 1999

[13]M. Piechowski, A ground coupled heat pump system with energy storage, PhD Thesis, The University of Melbourne, 1996

[14]H. Demir, A. Koyun, G. Temir, "Heat Transfer of Horizontal Parallel Pipe Ground Heat Exchanger and Experimental Verification", Applied Thermal Engineering 29 (2009), pp. 224-233 